\title{
Characterization of Lignocellulosic Fibers Reinforced with Poly(vinyl alcohol)
}

\author{
Manasa V Anand *, R Ravishankar, Kiran S Vasist, Madhu H N \\ R \& D Center, Department of Biotechnology, Dayananda Sagar College of Engineering, Bengaluru 560078, Karnataka, India
}

\begin{abstract}
The demands for materials made of plastics are rapidly increasing, especially in food packaging application. Recently, attention has been drawn to the use of bio-reinforced composites in packaging, automotive, medical and construction applications due to increased concern for environmental sustainability. Poly(vinyl alcohol) (PVA) films reinforced with crystals (unbleached) prepared by solution casting method possessed significantly improved properties compared to film reinforced with cellulose (bleached). From the results, PVA films with the addition of $4 \%(\mathrm{w} / \mathrm{w})$ of crystalline cellulose exhibited best combination of properties. In addition to good mechanical properties, this composite has good water resistance and biodegradability. The water absorption of biocomposite was found to be $22.63 \%$. From $\mathrm{X}$ - ray diffraction (XRD) analysis, diffraction peaks of biocomposite was observed at $2 \Theta=22.4384$. From scanning electron microscopy (SEM) analysis it was found that fractures at surfaces of biocomposite film were smooth and even without any porosity and uniform dispersion of jute crystals in the matrix.
\end{abstract}

Keywords: Bio-reinforced composites, poly(vinyl alcohol), glycerol, citric acid

Correspondence to: Manasa V Anand, R \& D Center, Department of Biotechnology, Dayananda Sagar College of Engineering, Bengaluru 560078, Karnataka, India; E-mail: manasa-bt@dayanandasagar.edu

Received: September 19, 2020; Accepted: April 7, 2021; Published Online: May 11, 2021.

Citation: Manasa, V.A., Ravishankar, R., Kiran, S.V., Madhu, H.N., 2021. Characterization of Lignocellulosic Fibers Reinforced with Poly(vinyl alcohol). Applied Environmental Biotechnology, 6(1): 6-15. http://doi.org/10.26789/AEB.2021.01.002

Copyright: Characterization of Lignocellulosic Fibers Reinforced with Poly(vinyl alcohol). (C) 2021 Manasa V Anand, R Ravishankar, Kiran S Vasist, Madhu H N. This is an Open Access article published by Urban Development Scientific Publishing Company. It is distributed under the terms of the Creative Commons Attribution-Noncommercial 4.0 International License, permitting all non-commercial use, distribution, and reproduction in any medium, provided the original work is properly cited and acknowledged.

\section{Introduction}

Biodegradable materials have excellent biocompatibility and physio-chemical properties. It has been extensively applied in the packaging, agriculture and biomedical fields. Crystalline cellulose was chemically derived from jute. The use of poly(vinyl alcohol) (PVA) particularly in commercial industry has arisen worldwide due to their unique chemical and physical properties, as well as being nontoxic, highly crystalline, and water-soluble polymer and having good filmforming and high hydrophilic properties (Vroman and Tighzert, 2009).

PVA composites prepared with these crystalline cellulose showed significantly improved tensile and thermal properties. PVA is a water-soluble and biodegradable polymer with excellent chemical resistance; as such it is an interesting material for high-tech applications (Gilberto et al,2010).

The plasticized PVA films were prepared by the casting method using glycerin as the plasticizer. The plasticized PVA had lower strength and higher elongation at break, lower degree of swelling and higher solubility than PVA. Glycerol is used as plasticizer to improve the thermal properties and mechanical properties of PVA. Glycerol interacts with PVA molecules and replaces hydrogen bonding within PVA molecules. Citric acid is inexpensive and non-toxic chemicals that have been used to improve the performance properties of cellulose. Sulphuric acid is used to precipitate and crystallize jute fibers and $\mathrm{NaOH}$ is used to neutralize jute fibers (Lani et al., 2014).

Due to the environmental concerns, availability, renewable feed stocks, relatively low cost and biodegradability, the use of natural fibers as reinforcements in polymers and composites has attracted much attention. Because of their very good mechanical properties crystalline cellulose (both nano and microcrystalline) has generated a great deal of interest as a source of micrometer and nanometer sized fillers (Samir et al., 2005).

The percentage of crystallinity of jute fiber $(73.4 \%)$ was considerably higher than that of other non - woods. Jute is another important source of cellulose (Rahman et al., 2014). The synthetic polymers and natural polymers which contain hydrolytically or enzymatically labile bonds or groups are degradable. The synthetic polymers have the advantages of predictable properties, batch to batch uniformity and can be tailored easily (Nair and Laurencin, 2007). But they are quite expensive. Hence this reminds of focusing on the natural polymers that are inherently biodegradable and can be promising candidates to meet different requirements (Chiellini and Solaro, 1996).

The flexural strength and the mechanical properties of jute reinforced polyster composites can be increased by using polyvinyl acetate plasticized or used in its commercial form as an emulsion as jute cloth in polyester resin. By calendaring the cloth prior to spraying with polyvinyl acetate the 
impact energies and tensile strengths of these components were greatly improved (Semsarzadeh, 2006).

The calendering of jute cloth results in the orientation of fibers in turn allowing more efficient packing and less microvoids in the final composite, lower water absorption, lower soluble matter lost and higher mechanical properties. To increase the adhesion of fibers in the cloth that prevents them from braking and makes them partly inaccessible to water during water immersion tests, jute fiber coated with polyvinyl acetate can be used (Semsarzadeh, 2006).

For surface modification of jute fibers such as grafting, mercerization, oxidation, ultraviolet and gamma radiation which are commonly used to improve the interfacial adhesion between jute fibers and polymer matrices various type of surface modification techniques were used (Khan, 2014).

By most conventional plastics processing techniques with some adjustments of processing conditions and modification of machinery biodegradable polymers can be processed. The techniques used in processing are film extrusion, injection moulding, blow moulding and thermoforming. Medicine, packaging and agricultural sectors have introduced biodegradable polymers. The application of biodegradable polymers not only include pharmaceutical devices as matrices for enzyme immobilization and controlled - release devices but also therapeutic devices as temporary prostheses, porous structure for tissue engineering (Catro et al., 2008).

Since biopolymers have a low solubility in water with a strong water uptake, they can be used as absorbent materials in horticulture, healthcare and agricultural applications (Suda et al., 2000). For the controlled release of drugs inside the body or as absorbable sutures, biodegradable polymers are used as implantable matrices (Middleton and Tipton, 1998).

The preparation and properties of biodegradable film composite using modified cellulose fiber reinforced with PVA was studied and observed that the percentage of modified cellulose increased due to better properties showed by film composites which indicate the importance of modified cellulose as a reinforcing agent (Laxmeshwar SS et al., 2012). Cellulose microfibers (CMF)/Poly ethylene-co-vinyl acetate (EVA) composites was prepared with different weight percentage of CMF for analyzing the CMF - EVA interaction and application of these composites as food packaging materials it was studied for swelling parameters, diffusion co efficient and oxygen transmission rate (OTR) and a uniform distribution of CMF in EVA was observed (Sonia and Dasan, 2013).

The preparation of cellulosic fibers reinforced composites blend films of starch - PVA by using citric acid as plasticizer and gluteraldehyde as the cross - linker was reported (Priya et al., 2014).

Due to potential applications in the fields related to environmental protection and the maintenance of physical health, biodegradable polymers have received much more attention in the last decade. There are limited groups of biopolymers which are of market importance. It is due to the fact of price level which is not yet competitive. It is not only dependent on competitiveness but also on the ability of the society to pay for it. The outlook for development in the field of biopolymer materials is bright and promising. Many methods have been developed like random and block copolymerization or grafting to improve the mechanical properties of biodegradable polymers. To prepare biodegradable materials with different morphological and physical characteristics, physical blending is another route. Some advanced technologies have been applied to provide added value to biodegradable polymers. These include active packaging technology and natural fiber reinforcements. There are several studies concerning the use of nanoclay with biodegradable polymers especially emphasizing with starch and aliphatic polyesters (Isabelle et al., 2009). Hence in this study we concentrated on an innovative biodegradable packaging materials using jute fibers reinforced with PVA and studied its various properties in order to evaluate its use in various fields of life.

\section{Materials and Methods}

\subsection{Materials and chemicals}

Jute was purchased from laxmi provisional store Bangalore, India and wasused as raw materialin this study. Glycerol, citric acid, sulphuric acid, sodium hydroxide, sodium chloriteand PVA was purchased from VASA Scientifics ltd., Bangalore, India. All the chemicals are reagent grade andwere used as received.

\subsection{Experimental procedure: process optimization}

Jute fibers were cut in small pieces and grinded in mixer. The dispersion and stirring of jute fibers in distilled water was carried out with the help of magnetic stirrer for 1 hour at $85^{\circ} \mathrm{C}$. Alkali treatment was done with $\mathrm{NaOH}$ with the help of magnetic stirrer for 1 hour at $80^{\circ} \mathrm{C}$. Then the jute fibers were bleached with $\mathrm{NaClO}_{2}$ for 1 hour at $80^{\circ} \mathrm{C}$. The above solution was then treated with concentrated $\mathrm{H}_{2} \mathrm{SO}_{4}$ for 1 hour. Later neutralization of the solution was carried out by adding $\mathrm{NaOH}$. The crystalline cellulose was then washed and centrifuged at $8,000 \mathrm{rpm}$ for 10 minutes. The PVA solution was prepared by dissolving PVA in distilled water by mechanical stirring at $85^{\circ} \mathrm{C}$ for 30 minutes. Glycerol was then added to the above solution and stirred for 30 minutes at $85^{\circ} \mathrm{C}$. Crystalline cellulose was added to the prepared PVA-Glycerol solution and stirred for 30 minutes at $85^{\circ} \mathrm{C}$ with the help of magnetic stirrer. The above solution was casted in moulds and incubated in the incubator for 48 hours. Characterization by fourier transform infrared spectroscopy (FTIS) method, water absorption capacity test, mechanical properties test, $\mathrm{X}$ - ray diffraction (XRD), scanning electron microscopy (SEM) analysis and soil burial degradation test were performed. Membrane with the best properties was chosen and casted into desired moulds, dried and peeled off. Jute-PVA biopolymer can be used as food packaging material. 


\subsection{Extraction of Crystalline Cellulose from jute fibers}

Jute fibers were subjected to a washing pre-treatment to remove impurities and waxy substances covering the external surface of fiber cell walls. The fibers were cut into small size (about $2 \mathrm{~cm}$ ) by using scissors and then milled into fine size by using a mixer. These fibers were dispersed in distilled water $(500 \mathrm{ml})$ for 10 minutes at room temperature and stirred for 1 hour at $50^{\circ} \mathrm{C}$ using a glass rod and filtered in order to remove soluble extracts in water. The dried fiber was mercerized with $2 \% \mathrm{NaOH}$ solution at $80^{\circ} \mathrm{C}$ for 2 hours with mechanical stirring followed by thorough washing until neutralized (Rahman et al., 2014). Two sets of crystalline cellulose were obtained i.e. bleached and non-bleached. The dried fibers were bleached with $2 \%$ (w/w) $\mathrm{NaClO}_{2}$ at $80^{\circ} \mathrm{C}$ for 2 hours with mechanical stirring. The fibers (bleached and non-bleached) were separately treated in concentrated sulfuric acid solution (40\% (w/w) Sulfuric acid in water) at $45^{\circ} \mathrm{C}$ for 2 hours with mechanical stirring. The ratio of fibers to acid solution was 1:15 g/l. After the treatment, the hydrolyzed cellulose samples were neutralized by $30 \%(\mathrm{w} / \mathrm{w})$ $\mathrm{NaOH}$ solution in water, and then the crystals were washed for four times.

After each washing step, the crystals were separated from the solution by centrifugation at $8,000 \mathrm{rpm}$ for 10 minutes. Finally, the crystals were obtained after drying in incubator for 48 hours (Rahman et al., 2014).

\subsection{Preparation of PVA solution}

An aqueous solution containing PVA and distilled water was prepared. PVA solution was prepared by dissolving PVA powder in $100 \mathrm{ml}$ distilled water at $85^{\circ} \mathrm{C}$ for 30 minutes, while being stirred with a mechanical stirrer until PVA particles were completely dissolved in water. The solution was stored in a glass bottle for further use (Rahman et al., 2014).

\subsection{Preparation of Crystalline Cellulose - reinforced PVA film}

PVA solution was further used to prepare PVA film by adding glycerol and citric acid and the mixture is again stirred at $85^{\circ} \mathrm{C}$ for 30 minutes. Poly(vinyl alcohol) - Crystalline Cellulose (PVA - CC) biocomposites with various filler contents were prepared by mixing the various amounts of crystalline cellulose in PVA using a magnetic stirrer. Citric acid worked as a cross linker of crystalline cellulose with PVA for the preparation of final composites. With constant stirring, these suspensions were poured into different PVA solutions for different compositions of the composites (Rahman et al., 2014). The stirring was performed at $85^{\circ} \mathrm{C}$ for 1 hour. The mixture was cooled at room temperature, then cast on acrylic moulds and incubated in incubator at $30^{\circ} \mathrm{C}$ for 48 hours. The dried films were stored in incubator at room temperature for further use.

\subsection{Optimization of process parameters}

Statistical analysis was carried out using Statistical software MINITAB. "MINITAB18" software was used to check various concentrations of crystalline cellulose, PVA, glycerol and citric acid was obtained and different composition of the CC/PVA composites were prepared as shown in Table S1.

\subsection{Characterization}

\subsubsection{Fourier transforms infrared spectroscopy}

The sample was prepared wherein membrane was homogenized well by using mortar and pestle. The IR 50 software was installed in the computer to measure the FTIR spectra. The sample was placed in the sample holder of the (Magna IR560) Fourier transforms infrared spectroscopy (FTIR) instrument. The blank scan was performed between $400 \mathrm{~cm}^{-1}$ - $4000 \mathrm{~cm}^{-1}$, to remove the background noise. The spectrum of the sample was measured against blank, by clicking 'Scan' button. The spectrum was obtained as a graph of percentage of transmittance versus wave number (Rahman et al., 2014).

\subsubsection{Mechanical properties}

The width and thickness of flat specimens at the center of each specimen was measured and within $5 \mathrm{~mm}$ of each end of the gage length. The membrane was cut in the shape required for analysis. Specimen was placed in the grips of the testing machine (care was taken to align the long axis of the specimen and the grips with an imaginary line joining the points of attachment of the grips to the machine). Extension indicator was attached. Speed of testing was set and machine was switched on. Load - extension curve of the specimen was recorded. Load and extension at the moment of rupture was recorded (Krumova et al., 2000).

\subsubsection{X-ray diffraction study}

The sample was ground by using mortar and pestle to a fine powder. The ideal sample will be a crystalline powder that has been pressed into the sample holder, have a smooth surface, and hold in the sample at an angle of $45^{\circ} \mathrm{C}$. More the crystalline the material, better will be the results.

Green 'door open' button on the right hand side of instrument was pressed. Gently handles were pulled out toward us and door was opened. Sample was installed by holding it in place with one hand and with the other, pressing the stage up until it locks. The silts in the 'anti-scattering' and 'detector' positions were verified as per requirement. The holder was labelled with sample number using tape and indelible marker. Desired sample number was entered into X-ray diffraction machine to identify electronic output and analyzed (Rahman et al., 2014).

\subsubsection{Scanning electron microscopy}

The sample was kept in desiccator for 72 hours. Then the sample coating was carried out. As sample is insulator, it 
should be coated with conductive material i.e $\mathrm{Au} / \mathrm{Pd}$ or carbon. Gold was used to coat the sample. About 1.0-1.5 minutes of sputtering was enough to apply metal to conduct the SEM electrons to ground and prevent charging without noticeably altering the topography of substrate.

The sample was placed in SEM analysis chamber. Striking the plasma inside the chamber was carried out by turning on the power switch. The vacuum level was maintained at around 150 millitorr. The high voltage control was switched on. Then the high voltage control knob was turned until the plasma discharge current meter reads $20 \mathrm{~mA}$. When the deposition time was up, the high voltage was turned off to zero (Luo, 2008).

\subsubsection{Water uptake study}

A water uptake test was performed to observe the water absorption and sustainability in water. Pre-weighed composite films with various crystalline cellulose loading were taken and soaked in water for a different time period (5-150 minutes). The membrane of different concentration was cut in small segment of about $2 \mathrm{~cm}$. Weight of all the samples was determined. The Membranes were soaked in petriplate containing water. The Membrane was weighed (in grams) after an interval of 15 minutes, 30 minutes, 45 minutes, 1 hour, 1.5 hours respectively. The graph was plotted for weight against time (Rahman et al., 2014).

\subsubsection{Soil burial degradation study}

Garden soil (1200 g) was taken in different pots. Weighed amount (1 g) of each of the sample was determined. The Membrane of different concentration was cut into small pieces. The pots were covered with the aluminum foil and kept at room temperature. The weights of all the samples were taken at regular interval of time (10 days) to check for any weight loss. Percentage weight loss as a function of number of days was determined (Rahman et al., 2014).

\section{Results and Discussion}

\subsection{Swelling properties}

Figure 1 displays effect of different crystalline cellulose concentrations on water uptake percentages of the biopolymer films for the following samples: sample 1 - $4 \mathrm{~g}$ PVA, $1 \mathrm{~g}$ glycerine, 2 g citric acid, 5 g bleached bellulose crystals; sample 2 - 4 g PVA, 1 g glycerine, 2 g citric acid, 2 g crystalline cellulose; sample 3 - 4 g PVA, 2 g citric acid, $1 \mathrm{~g}$ glycerine; sample 4 - 4 g PVA, 1 g glycerine, $2 \mathrm{~g}$ citric acid, 4 $\mathrm{g}$ crystalline cellulose. As can be seen in this figure, incorporation of $\mathrm{CC}$ reduced swelling percentage of the biopolymer films, and the lowest amount of water sorption relates to biopolymer nanocomposite films containing 5\% CC. Reduction in swelling value could be mainly due to distribution of $\mathrm{CC}$ particles into biopolymer matrix and formation of strong interaction between filler-polymer matrixes (Rahman et al., 2014).

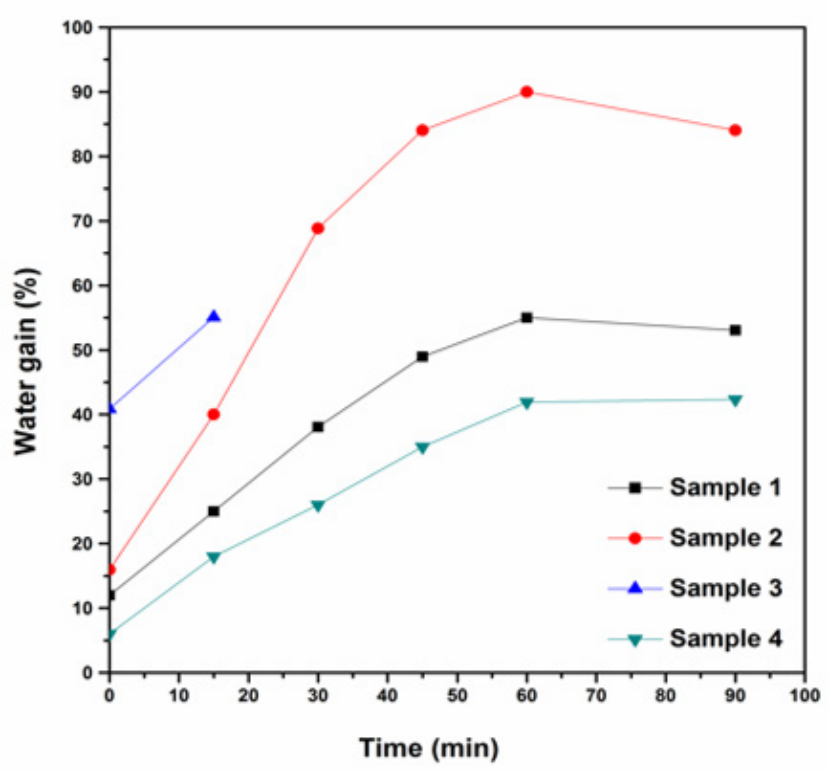

Figure 1. The effect of MCC content on water gain of PVA crystalline cellulose biocomposite films

\subsection{X-ray diffraction analysis}

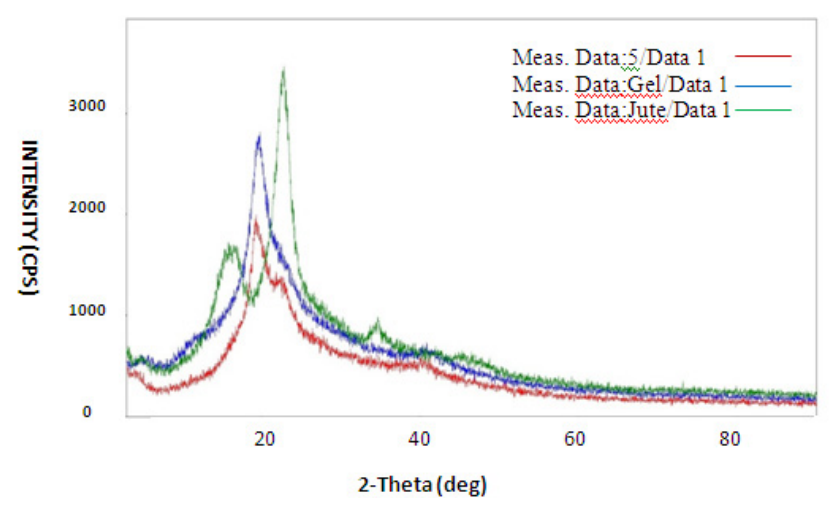

Figure 2. X-ray diffraction patterns for membrane, PVA gel, crystalline cellulose

Crystalline peak of Jute fibers treated with sodium hydroxide and sulfuric acid, appear as a doublet at $2 \Theta=16.07^{\circ}$ and $22.95^{\circ}$ (Figure 2 ) a significant variation in the diffraction pattern of Cellulose fibers can be explained by the replacements of $\mathrm{OH}$ groups by $\mathrm{ONa}$ groups during alkali treatment. Subsequent rinsing with water will remove the linked $\mathrm{Na}$-ions and thus causing the cellulose to be converted to a new crystalline structure.

The crystalline regions of the composites behave as barriers and any change in crystallinity may affect the final properties of the composite film. Since Biofilm composite has a higher degree of crystallinity than PVA film, a higher water resistance would be expected as water absorption occurs almost entirely in the amorphous region of a polymeric system (Sionkowska et al., 2009). 


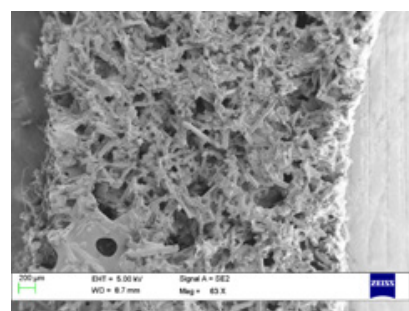

(a)

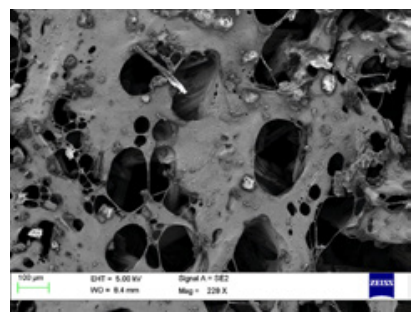

(e)

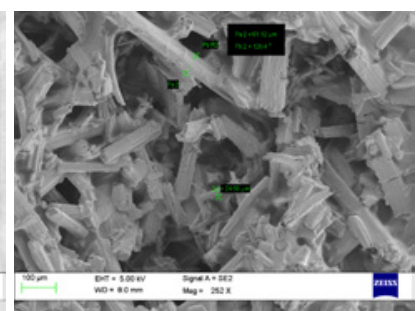

(b)

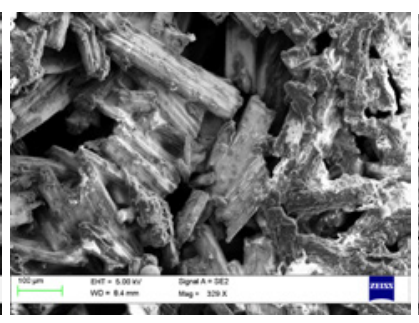

(f)

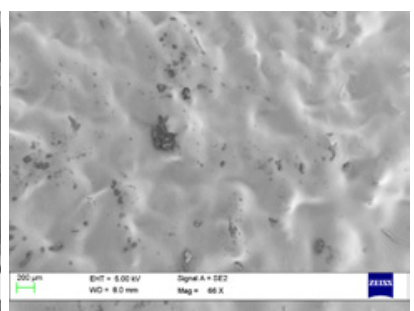

(c)

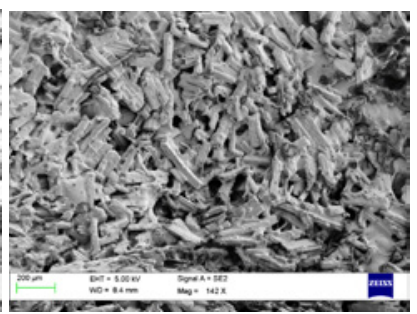

(g)

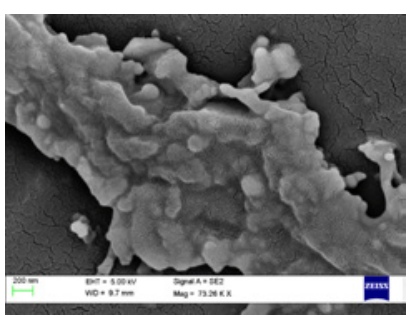

(d)

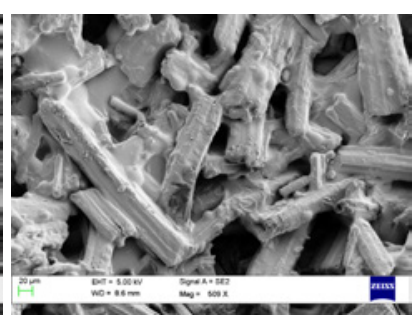

(h)

Figure 3. SEM images of films: (a) and (b) - $4 \mathrm{~g}$ PVA, $4 \mathrm{~g} \mathrm{CC}, 1 \mathrm{~g}$ glycerine and $1 \mathrm{~g}$ citric acid; (c) and (d) - $4 \mathrm{~g}$ PVA, $1 \mathrm{~g}$ glycerine, $2 \mathrm{~g}$ citric acid and $2 \mathrm{~g} \mathrm{CC}$; ( e ) and ( f ) - $4 \mathrm{~g}$ PVA, $5 \mathrm{~g}$ bleached CC, $1 \mathrm{~g}$ glycerine and $2 \mathrm{~g}$ citric acid; (g) and (h) - $4 \mathrm{~g}$ PVA, $1 \mathrm{~g}$ glycerine, $4 \mathrm{~g}$ $\mathrm{CC}$ and $2 \mathrm{~g}$ citric acid

\subsection{Scanning electron microscopy}

The SEM images of raw jute, mercerized jute fibers, $\mathrm{CC}$, and the composites are shown in Figure 6. It was observed from the figures that the CC appeared in micro rod like structures reinforced with PVA gel matrix, and the diameters of micro crystals were in the range of about 12-15, having an aspect ratio (1/d) around 4-6 (Figure 3(a)). Although it was expected there would be some nanocrystals after acid hydrolysis, they were not visible in any of the images as shown in Figures $3(\mathrm{~b}-\mathrm{h})$ which indicated that the crystals are microparticles. According to Su and Wu, SEM images of PVA and alkali lignin (AL)/PVA film samples depicted rough, irregular surface of reaction films when the samples were investigated for the surface morphology. We have assumed that the change of structures and size of the fibers have occurred due to the removal of the amorphous regions of the cellulose by acid treatment (Su and $\mathrm{Wu}, 2011$ ).

Figure 3 shows the SEM micrograph of the surface of the composite that revealed a rough and even surface with porosity and uniform dispersion of CC in the matrix at low $\mathrm{CC}$ concentration the microparticles were not visible and clusters of crystalline cellulose can be observed and linkage was ruptured. Consequently, this aggregation can destroy the film integration and created a rigid state in films. The fractured surfaces of the composite specimens were studied and shown in Figure 6 to understand the failure mechanisms and possible interaction between $\mathrm{CC}$ and PVA. The fracture surfaces of PVA-CC composites were also observed to be smooth and even, which indicates less amount of bonding between the reinforcement and the matrix.

\subsection{Water uptake study}

Comparing the water absorption capacity of PVA-Cellulose blend film and nanocellulose fiber reinforced with PVA-
Cellulose composite, it is noted that percentage of water absorption of all nanocellulose fiber reinforced film was lower indicating that films that contain nanocellulose have a good preventive ability against water. This result illustrates the water absorption properties were improved by the presence of nanocellulose fiber in the blend films. The possible reason for this kind of behavior was related to the formation of the network structure between the nanocellulose particles and PVA-cellulose component, which prevented the water resistance of the film. Some differences are observed by increasing $\mathrm{CC}$ content in PVA-Cellulose Films. It can be observed that the water absorption of PVA-Cellulose films increased from 22.63 to $31.43 \%$. It can be explained by the formation of some large accumulated particles, whereby the large accumulation of $\mathrm{CC}$ particles, whereby the large accumulation of CC particles can generate voids which can absorb water molecules and therefore increase in the percentage of water absorption (Rahman et al., 2014).

\subsection{Fourier transform infrared spectroscopy}

The fourier transform infrared spectroscopy (FTIR) spectra of crystalline cellulose and its composite sample are shown in Figure 4. The band for acetyl and uronic ester groups of the hemicellulose at $1,714 \mathrm{~cm}^{-1}$ was present in $\mathrm{CC}$, which indicates that the crystalline cellulose had few impurities. Moreover, there was absorption at $710 \mathrm{~cm}^{-1}$ and a weak shoulder at $750 \mathrm{~cm}^{-1}$ due to I $\alpha$ (triclinic) and $\mathrm{I} \beta$ (monoclinic) cellulose structure. The chemical treatment of raw jute for removing the lignin, the absorption bands in 1,730 $\mathrm{cm}^{-1}, 1,620 \mathrm{~cm}^{-1}, 1,595 \mathrm{~cm}^{-1}$ and $1,512 \mathrm{~cm}^{-1}$ corresponding to the functional groups of lignin, are not observed on the spectrum of CC. For the composite, the large band observed between $3,600 \mathrm{~cm}^{-1}$ and $3,200 \mathrm{~cm}^{-1}$ is linked to the stretching of $\mathrm{O}-\mathrm{H}$ from the intramolecular and intermolecu- 
lar hydrogen bonds, the vibrational band observed between $2,840 \mathrm{~cm}^{-1}$ and $3,000 \mathrm{~cm}^{-1}$ refers to the stretching $\mathrm{C}-\mathrm{H}$ from alkyl groups and the peaks between $1,750-1,620 \mathrm{~cm}^{-1}$ are due to the stretching $\mathrm{C}=\mathrm{O}$ and $\mathrm{C}-\mathrm{O}$ due to the formation of ester linkage between PVA and cellulose crystal. The peaks for C-O-C at $1,150 \mathrm{~cm}^{-1}-1,085 \mathrm{~cm}^{-1}$ and for C-O at $1,141 \mathrm{~cm}^{-1}$, bending vibration related to $\mathrm{CH}_{2}$ groups at $1,461 \mathrm{~cm}^{-1}-1,417 \mathrm{~cm}^{-1}$, are also observed in the spectrum of the composite. Furthermore, the composite spectra showed that the absorption at $705 \mathrm{~cm}^{-1}$ has disappeared from native PVA and the peaks at $512 \mathrm{~cm}^{-1}$ and $628 \mathrm{~cm}^{-1}-648 \mathrm{~cm}^{-1}$ are weakened. This region was similar to that of the cellulose crystal spectra. The weakness, disappearance, and shift of the characteristic absorption band might have resulted from the interactions of different $\mathrm{OH}$ groups in the PVA and cellulose crystal molecular chains This may indicate the development of new inter-molecular and intra-molecular hydrogen bonds and a change in the conformation between PVA and cellulose crystal (Krumova et al., 2000).

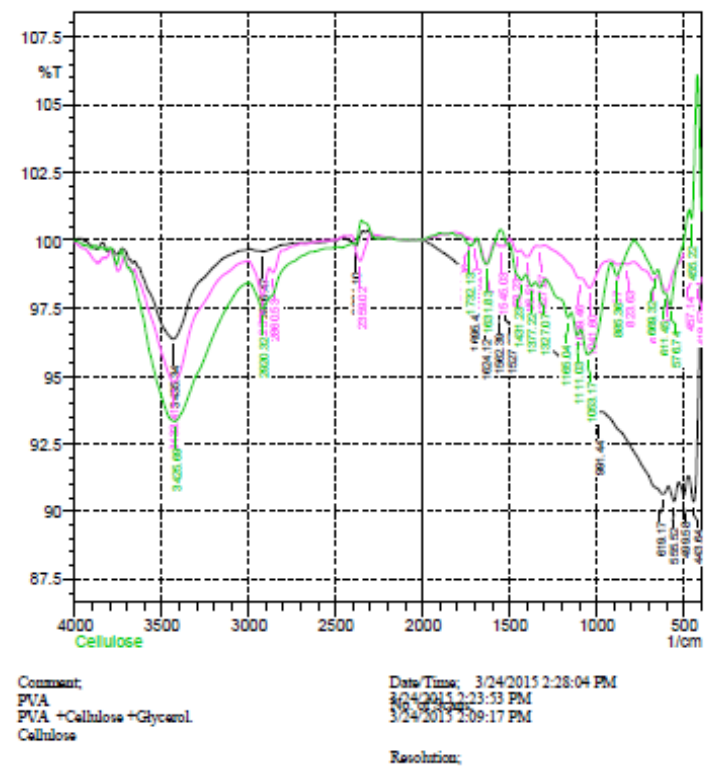

Figure 4. FTIR spectra of PVA, PVA + cellulose + glycerol, cellulose

From the FTIR analysis, it has been concluded that almost all the lignin and hemicellulose were removed after chemical treatment. This arises from the absence of the absorption bands in between $1500 \mathrm{~cm}^{-1}-1600 \mathrm{~cm}^{-1}$ and $1730 \mathrm{~cm}^{-1}$ $-1740 \mathrm{~cm}^{-1}$, which relates to the lignin and hemicellulose components, respectively. Therefore, it can be stated that the cellulose crystal obtained in this study was almost pure, which contains a very small amounts of lignin and other non-cellulosic substances.

\subsection{Mechanical properties}

The tensile strength of neat PVA film was 17.2 MPa. The tensile strength of cellulose crystal reinforced PVA films showed the highest value (43.9 MPa) at the loading of 9

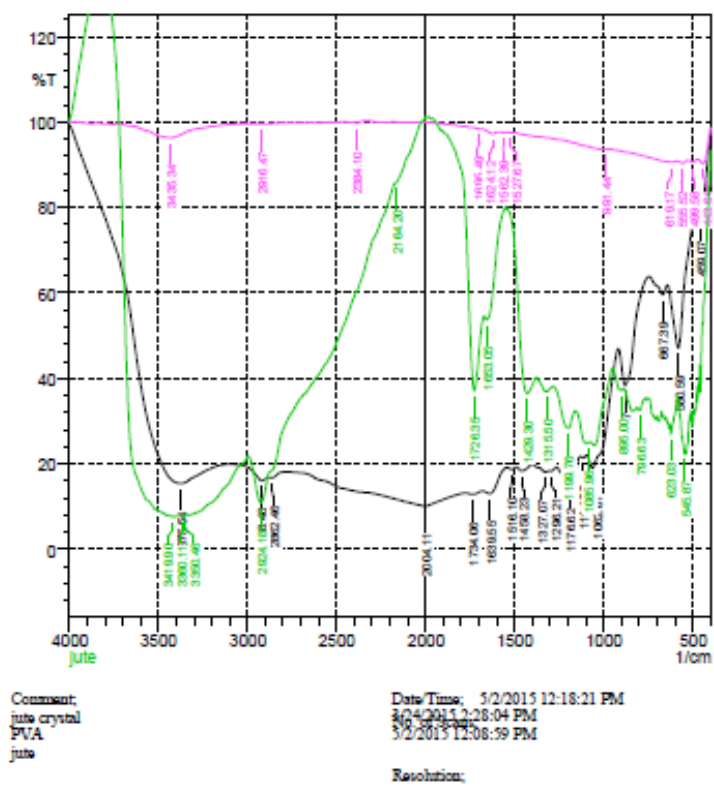

Figure 5. FTIR spectra of cellulose crystal, PVA, jute

wt.\%. This value was $155 \%$ higher than neat PVA film. However, the cellulose crystal loading of more than wt.\% to PVA matrix gradually decreased the tensile strength. The tensile strength of PVA films with $15 \mathrm{wt}$ \% cellulose crystal was $110 \%$ compared to PVA film. The intermolecular forces between CC and the base PVA matrix may enhance the tensile strength of the PVA composite films. The TM has increased from 1,472 to $2,190 \mathrm{MPa}$ for pure PVA film to $9 \%$ cellulose crystal containing composite (Li and Luo, 2011; Julinová et al., 2010).

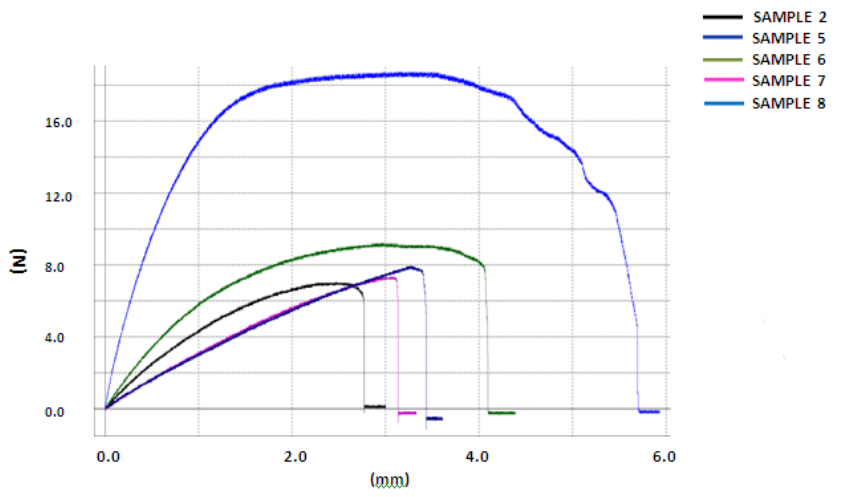

Figure 6. Comparative chart for tensile strength of different compositions of biocomposite film

It was obvious that if TS was increased, then $\mathrm{Eb} \%$ should be decreased and in this sample A yielded $\mathrm{Eb} 145 \%$ and sample D gave 3.7\%. The enhancement in tensile strength and elongation at break at low content of fillers The enhanced TS and TM resulting from the composites demonstrated (i) the reinforcing effect of finely dispersed high-performance $\mathrm{CC}$ throughout the polymer matrix and (ii) strong interaction between CC and PVA that ultimately enhances interfacial adhesion. 


\section{Conclusion}

In this work, the crystalline cellulose was extracted from jute by hydrolysis. The FT-IR, XRD and SEM analysis confirmed the presence of microstructures of CC.

From the FTIR analysis, it can be concluded that almost all the lignin and hemicellulose were removed after chemical treatment. This arises due to the absence of the bands of absorption in between $1500 \mathrm{~cm}^{-1}-1600 \mathrm{~cm}^{-1}$ and 1730 $\mathrm{cm}^{-1}-1740 \mathrm{~cm}^{-1}$, which relates to the lignin and hemicellulose components. It was observed that the water absorption of PVA-Cellulose films increased from $22.63 \%$ to $31.43 \%$. The large accumulation of CC particles can generate voids which can absorb water molecules and therefore increase in the percentage of water absorption.

\section{Conflict of Interest}

Author declares that there is no conflict of interest in the information presented here.

\section{References}

Catro, G., Panilaitis, B. and Kaplan, D., 2008. Emulsan tailorable biopolymer for controlled release. Bioresource Technology, 99(11): 4566-4571. https://doi.org/10.1016/j.biortech.2007.06.059

Chiellini, E. and Solaro, R., 1996. Biodegradable polymeric materials. Advanced Materials, 4: 305-313.

https://doi.org/10.1002/adma.19960080406

Gilberto, S., Julien, B. and Alain, D., 2010. LUFFA CYLINDRICA as a cellulose source of fiber, microfibrillated cellulose \& cellulose nanocrystals. Bioresources, 5(2): 727-740.

Isabelle, V. and Lan, T., 2009. Biodegradable Polymers. Materials, 2: $307-$ 344

https://doi.org/10.3390/ma2020307

Jahan, M.S., Saeed, A., Ni, Y., He, Z., 2009. Pre-extraction and its impact on the alkaline pulping of bagasse. Journal of Biobased Materials and Bioenergy, 3(4): 380-385.

https://doi.org/10.1166/jbmb.2009.1053

Julinová, M., Kupec, J., Alexy, P., Hoffmann, J., Sedlaík, V., Vojtek, T., Chromcková, J., and Bugaj, P., 2010. Lignin and starch as potential inductors for biodegradation of films based on poly(vinyl alcohol) and protein hydrolysate. Polymer Degradation \& Stability, 95(2): 225-233. https://doi.org/10.1016/j.polymdegradstab.2009.10.008

Khan, J.A., 2014. The use of jute fibers as reinforcements in composites. Biofiber Reinforcements in Composite Materials. https://doi.org/10.1533/9781782421276.1.3

Krumova, M., Lpez, D., Benavente, R., Mijangos, C., and Perea, J.M., 2000. Effect of crosslinking on the mechanical and thermal properties of poly(vinyl alcohol). Polymer, 41(26): 9265-9272. https://doi.org/10.1016/S0032-3861(00)00287-1

Lani, N.S., Ngadi, N., Johari, A., Jusoh, M., 2014. Isolation, Characterization, and Application of Nanocellulose from Oil Palm Empty Fruit Bunch Fiber as Nanocomposites. Journal of Nanomaterials, 3: 13. https://doi.org/10.1155/2014/702538

Laxmeshwar, S.S., Kumar, M.D.J., Viveka, S., Nagaraja, G.K., 2012. Preparation and Properties of Biodegradable Film Composites Using Modified Cellulose Fibre-Reinforced with PVA. Polymer Science, 2012: 1-8. https://doi.org/10.5402/2012/154314

Li, X.F, and Luo, X.G., 2011. Preparation and characterization of sodium lignosulfonate PVA blend films. CIESC Journal, 62(6): 1730-1735.

Luo, X.G., 2008. Textbook of High Purity Lignin Extraction and Thermoplastic Modified. Chemical Industry Press, Beijing.

Middleton, J.C. and Tipton, A.J., 1998. Synthetic biodegradable polymers as medical devices. Med. Plastics Biomater. Mag, 3: 30.

Nair, L.S., Laurencin, C.T., 2007. Biodegradable polymers as biomaterials. Progress in Polymer Science,32: 762-798. https://doi.org/10.1016/j.progpolymsci.2007.05.017

Priya, B., Gupta, V.K., Pathania, D., Singha, A.S., 2014. Synthesis, characterization and antibacterial activity of biodegradable starch/PVA composite films reinforced with cellulosic fibre. Carbohydrate Polymers, 109: 171-179. https://doi.org/10.1016/j.carbpol.2014.03.044

Rahman, M.M., Afrin, S. and Haque, P., 2014. Characterization of crystalline cellulose of jute reinforced poly(vinyl alcohol)(PVA) biocomposite film for potential biomedical applications. Progress in Biomaterials, 3(1): 23. https://doi.org/10.1007/s40204-014-0023-X

Samir, M.A., Alloin, F. and Dufresne, A., 2005. Review of recent research into cellulosic whiskers, their properties and their application in nanocomposite field. Biomacromolecules, 6(2): 612-626. https://doi.org/10.1021/bm0493685

Semsarzadeh, M.A., 2006. Low Cost, High Strength, Hard Cellulosic Fiber Reinforced Polyester Structures and Units. Polymer-Plastics Technology and Engineering, 24(4): 323-334. https://doi.org/10.1080/03602558508070071

Sionkowska, A., Planecka, A., Kozlowska, J. and Skopinska-Wisniewska, J., 2009. Photochemical stability of poly(vinyl alcohol) in the presence of collagen, Polymer degradation \& stability, 94(3): 83-388. https://doi.org/10.1016/j.polymdegradstab.2008.11.020

Sonia, A., Dasan, K.P., 2013. Celluloses microfibers (CMF)/poly (ethyleneco-vinyl acetate) (EVA) composites for food packaging applications: A study based on barrier and biodegradation behavior. Journal of Food Engineering, 118(1): 78-89. https://doi.org/10.1016/j.jfoodeng.2013.03.020

Su. H. and Wu. Y.F., 2011. Film drying problems in aqueous tape casting. Journal of Ceramics, 32(4): 512-517.

Suda, K., Wararuk, C. and Manit, S. Radiation modification of water sorption of cassava starch by acrylic acid/acrylamide. Radiation Physics and Chemistry, 59: 413-427. https://doi.org/10.1016/S0969-806X(00)00297-8

Vroman, I. and Tighzert, L., 2009. Biodegradable Polymers. Materials, 2: 307-344.

https://doi.org/10.3390/ma2020307 


\section{Supplementary materials}

Table 1: Composition of the CC/PVA composites

\begin{tabular}{ccccc}
\hline Sample Number & $\begin{array}{l}\text { Amount of cellu- } \\
\text { lose crystals (CC) } \\
\text { in grams }\end{array}$ & $\begin{array}{l}\text { Amount of PVA } \\
\text { in grams }\end{array}$ & $\begin{array}{l}\text { Amount of glyc- } \\
\text { erol in grams }\end{array}$ & $\begin{array}{l}\text { Amount of citric } \\
\text { acid in grams }\end{array}$ \\
\hline Sample 1 & 5 (bleached) & 4 & 1 & 2 \\
Sample 2 & 2 & 4 & 1 & 2 \\
Sample 3 & - & 4 & 1 & 2 \\
Sample 4 & 4 & 4 & 1 & 2 \\
\hline
\end{tabular}

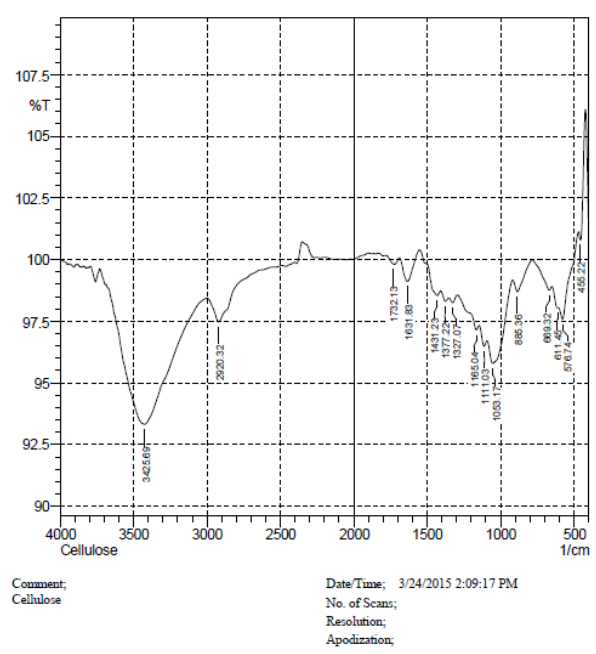

Figure 1: FTIR spectra of Cellulose crystal

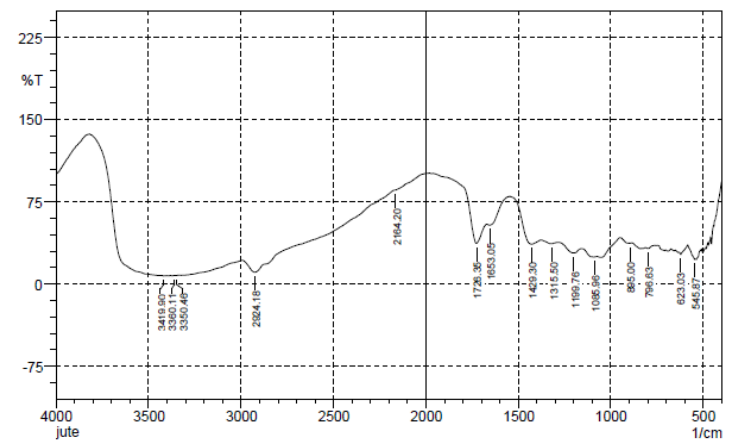

Figure 2: FTIR spectra of membrane( $4 \mathrm{~g}$ PVA, $4 \mathrm{~g} \mathrm{CC}, 1 \mathrm{~g}$ Glycerine, 2g Citric Acid)

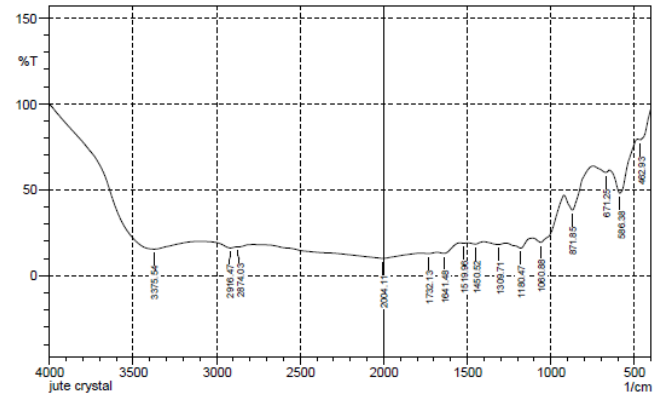

Figure 5: FTIR spectra of Jute crystal

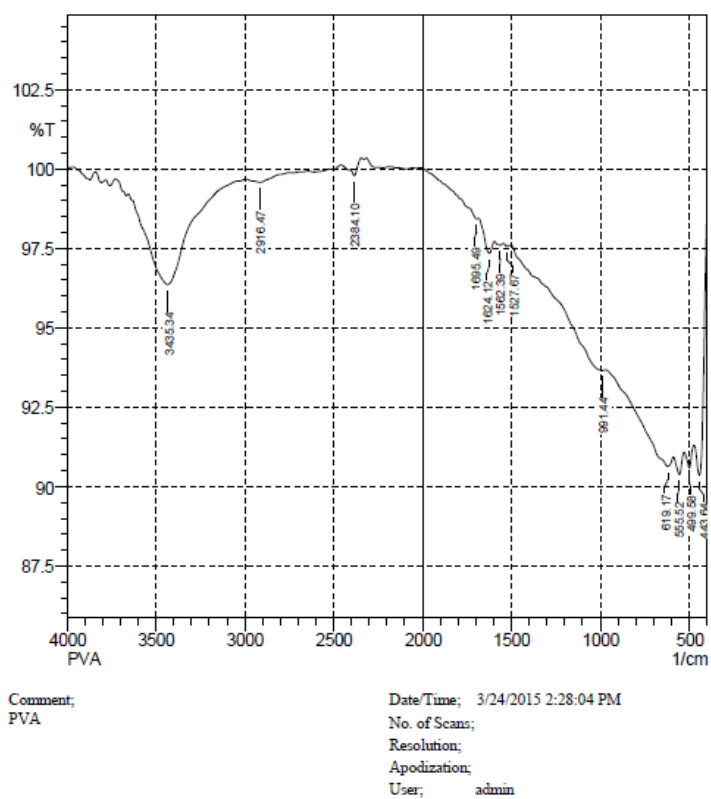

Figure 3: FTIR spectra of PVA Crystals

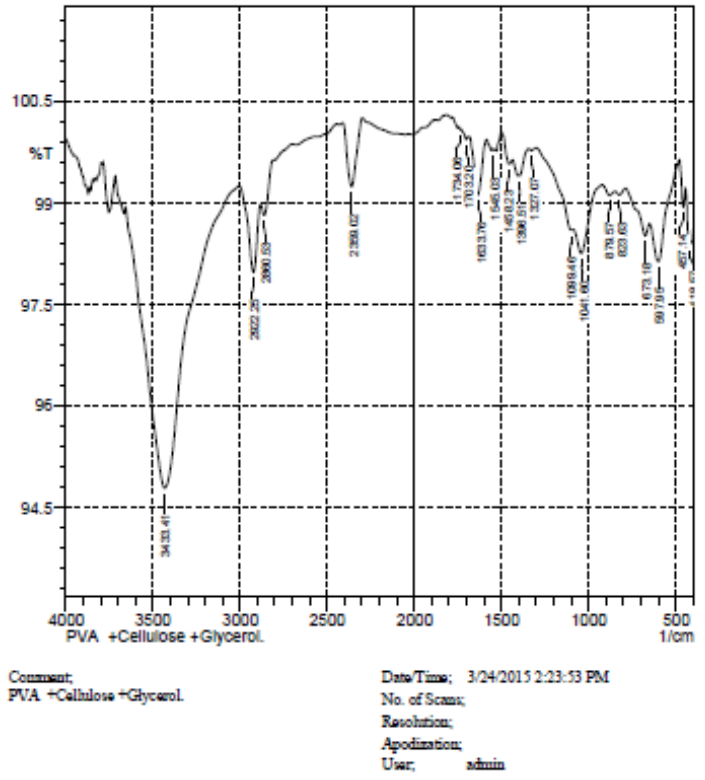

Figure 4: FTIR spectra of PVA+Cellulose+Glycerol 


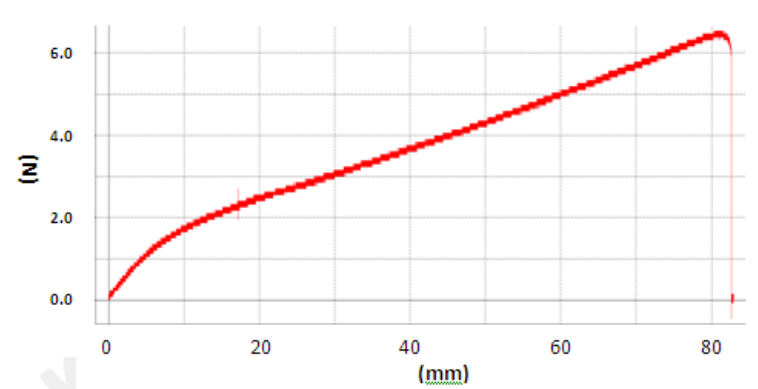

Figure 6: Tensile strength of film (4g PVA, $2 \mathrm{~g}$ Citric acid, $1 \mathrm{~g}$ Glycerin)

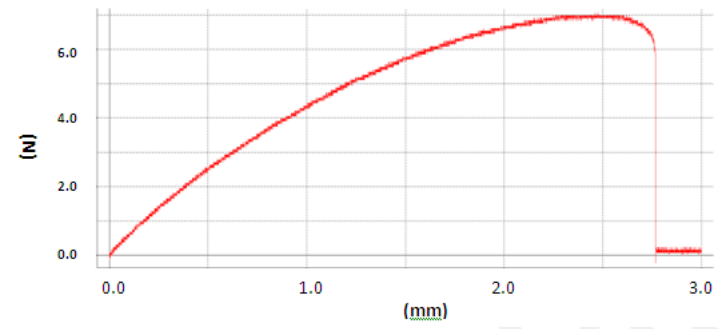

Figure 7: Tensile strength of film (4g PVA, 4g CC, 1 g glycerin and $2 \mathrm{~g}$ Citric acid)

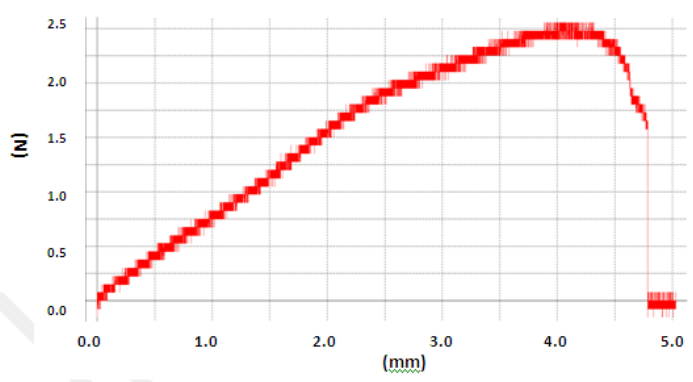

Figure 8: Tensile strength of film (4g PVA, $1 \mathrm{~g}$ Glycerin, $2 \mathrm{~g}$ Citric acid and $2 \mathrm{~g} \mathrm{CC}$ )

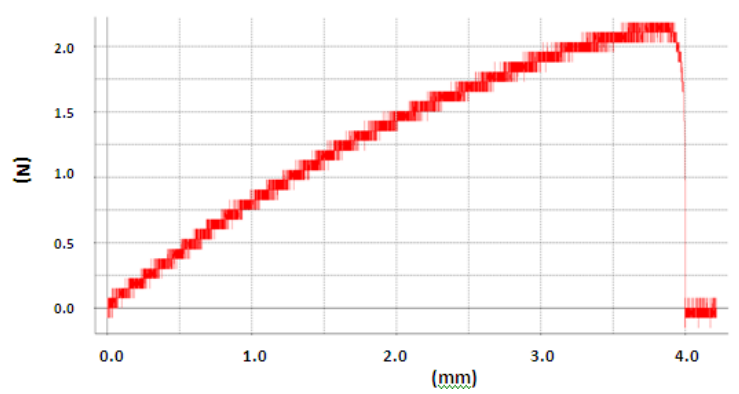

Figure 9: Tensile strength of film (4g PVA, $1 \mathrm{~g}$ Glycerin, $2 \mathrm{~g}$ Citric acid and $2 \mathrm{~g} \mathrm{CC}$ )

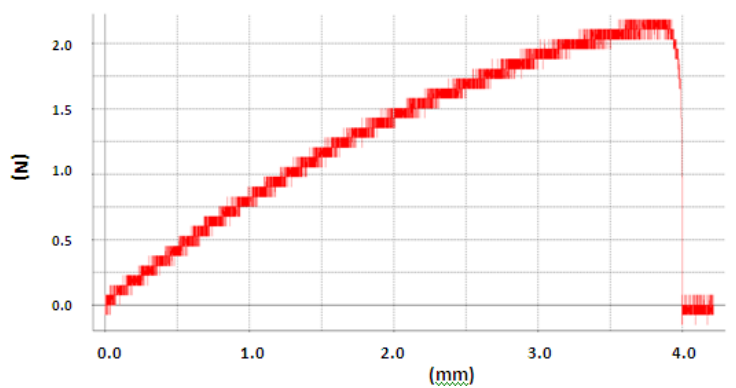

Figure 10: Tensile strength of film (4g PVA, 1g Glycerine, $2 \mathrm{~g}$ Citric acid and 5g Bleached CC)

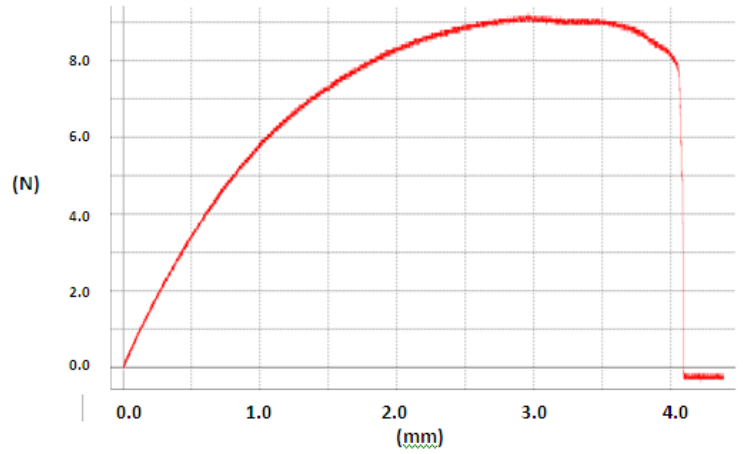

Figure 11: Tensile strength of film (4g PVA, 4g CC, $1 \mathrm{~g}$ Glycerin and 2g Citric acid)

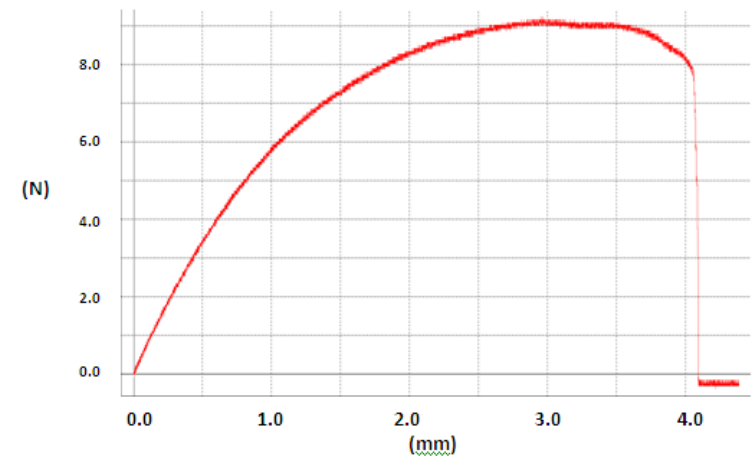

Figure 12: Tensile strength of film (4g PVA, $1 \mathrm{~g}$ Glycerin and $4 \mathrm{~g} \mathrm{CC})$

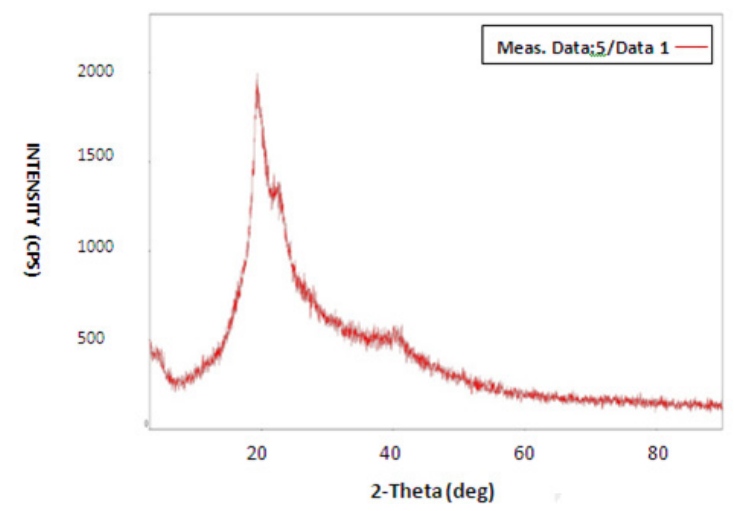

Figure 13: X-ray diffraction patterns for membrane (4gPVA, $4 \mathrm{~g} \mathrm{CC}, 1 \mathrm{~g}$ Glycerin and 2g Citric acid) 


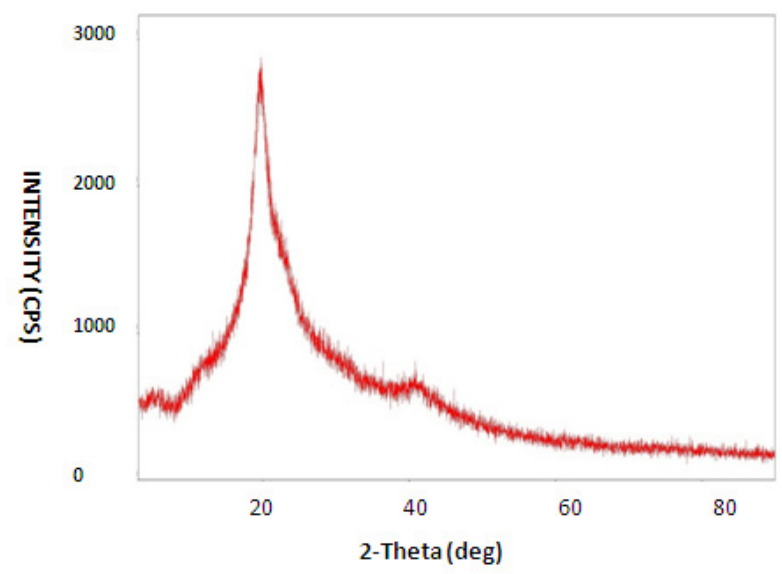

Figure 14: X-ray diffraction patterns for PVA gel

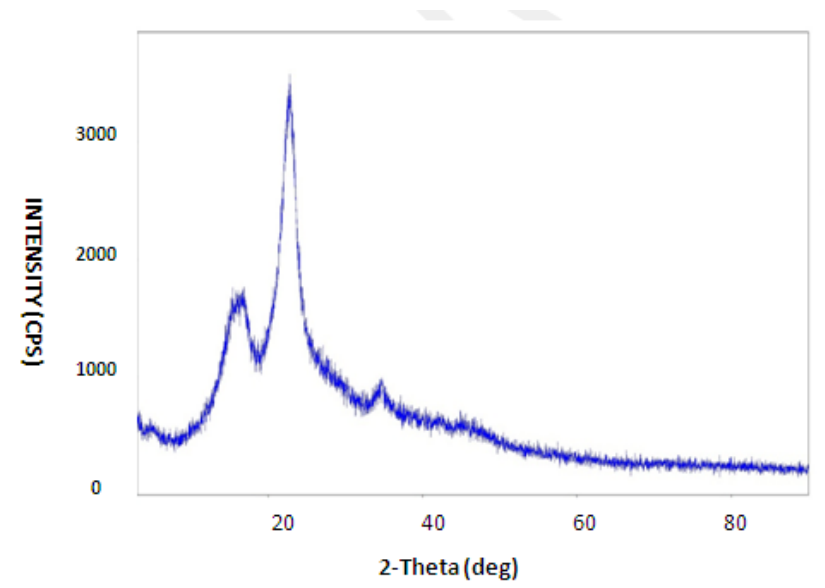

Figure 15: X-ray diffraction patterns for cellulose crystals 